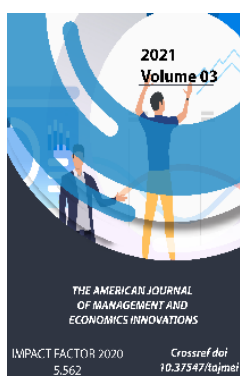

\title{
Effective Role Of Forecasting And Decision Making In Organization Of Borno State
}

\author{
Umar Mohammed Ali
}

PhD Student Of City University Cambodia

\section{ABSTRACT}

Forecasting is the Act of anticipating in advancement is likely to happen under a given sat to condition is very important not only to every business organisation but to virtually every significant management decision. The framework of this paper is focus on the nature of the forecasting and the role of the forecasting techniques, which include the qualitative and quantitative, the criteria for choosing forecasting technique and the failure of the business forecasting techniques. However, perfect forecasting is usually impossible because there are so many factor in the business environment that can not be fully predicted with certainty, therefore rather than search for the perfect forecasting, which is more important is to establish the practical of continual model or methodology but we should try to chose the best forecasting method in making decisions in an organisation.

\section{KEYWORDS}

Forecasting, Management, Decision ,Organisation ,The Role, Forecasting Model,Economic.

\section{INTRODUCTION}

A decision is a choice between two or more alternative decision making is the process of through and deliberations that lead to a decisions, from the above statement it is clear that human beings are always engaged in making decision in one way or the other. Not necessary conclusions of that fact that they are doing so. All of this decisions that we make are either consciously or unconsciously. In other words, some are routine while other are nonroutine, what clothes shall we put no? What 
shall we take for break fast? And so on and so forth are some of the decisions that are made on daily basis. Such as decision are repetitions and are therefore termed routine. Other decision present a greater range of choices where the alternative are not clearly defined. In such cases, we normally rationalize the situation in some ways, these types of decision are classified as non routine since they are made on a recurrent basis in fact, decision by management are classified under these headings.

\section{FORECASTING}

Literally, it's possible to make a forecasting about any thing in the future we daily and listening to weather forecast. Also numerous, analysis forecast the movement of the stock market and for an organisation stock or for industrial stocks. The concern of management is with specified type of forecast judgement to any decisions that they have. These are discussed as follows.

\section{ECONOMIC FORECASTING}

Probably no single factor is more important in managerial planning of the level of future business activities. The economic forecast is necessary and an important tool for the managers. Economic forecast provide climate. Thus, the process of economic forecasting is essential to the managers thinking in making decision on regarding the sure. It's usually not an easy task to make a forecast of an economy of the dynamic and complex nature, the precaster must attempt to determine the level of the major constituent of the economic consumer disposal income, business expenditure on plants and machineries, government expenditure and others.

\section{SALES FORECASTING}

The sales forecasting is specifically estimated venture derived by a company from sales of a product and group of product for a given period of time. The sales forecasting is probably the most statistics in any company planning.

It's is the basis for many important decision, including the level of production, size of the work force, investment in plant and equipment and level of marketing efforts.

The sales forecast provides an important basis of cash flow projections and estimates of profitability, which in turns, becomes a guideline for an important decision, virtually, all aspects of company's operation become geared towards the forecast level of sales. Sale forecast is not merely a matter of starting that we anticipate a certain number of unites to be sold, or that the sale must be sub-divided according to product lines, regions, customers, and organisation units or profit centres.

As with the economic forecasting, the process of the forecasting is not easy it would be impossible to arrive at a reasonable decision about the operations of the enterprise without forecast; the forecast is an integral of planning function of the management of any enterprise.

\section{TECHNOLOGICAL FORECASTING}

In recent times increasing emphasise has been made on technological forecasting elevation as it is so in a very high forecasting has become so necessary as a result of a repaid increasing pace of technology and dynamic nature management must attempt to predict it's development undoubtedly, management is interested in this type of forecasting system for the need to keep abreast of technological changes in order to remain competitive nothing can be move damaging to an enterprises than to allow others in the same industry or product line to get jump on new production to forecast techniques. It becomes a matter of self preservation to forecast technological the production of enterprise will be presented on some assumption about the future technology. 


\section{THE ROLE OF FORECASTING IN MANAGEMENT}

The importance of forecasting comes from the necessity of planning and it's equivalent, the need for planning comes from the necessity to work today an activities they are intended to meet future demand, forecasting is made because the efficient use of resources depends on so much allocated and scheduling to meet the coming conditions most forecast are directly towards estimating future demand sale.

Since it is known how uncertain the future can be have the repercussions of decision to be taken could be very devastating for an enterprise, the will be prudent together information and construct an alternative estimate of differing possibilities using differing hypothesis in other words, "the objective of forecasting as to minimize uncertainly and identity and evaluate risk" since decisions are based on forecasts the objective of forecast must be help the decision maker to adopt the best solutions. The decisions maker needs to have his doubts and uncertainty about the future reduced, if not eliminated and also sufficient information so provide the forecast in solving the problem.

Because of the varying degrees of uncertainly, the decision maker will also need to know how must important attached to alternative decisions to this tools. Is a function of forecasting and the forecaster will need to identify those factors which are more uncertain than other and also to point out the consequences of a mistaken forecast no management can escape the need to predict Not to forecast is really to assume indefinite continuations of the statuesque in the dynamic time to expect no change in very short time is sighted an unrealistic for management a forecast is a means of end no an it self management help in achievement of this success.

\section{FORECASTING RETURNS}

Forecasting returns under the assumption that all policies concerning returns been determined and data collection on return has started. The first step in any forecasting exercise is to build a forecast model that models the variable to be predicted as a function of the explanatory variable (Box and Jenkins, 1976). For example, the next period and the explanatory variables can past sales.

This forecaste model will have a number of parameters that need to be establish using historical sales and return data. We have a fully specified forecast model.

As the second step, forecasts of return are made using parameters estimates obtained from this forecast model and historical information. The two subsections to follow describe methods for these two step respectively. Table list the main notation that is used in this section.

\section{FORECAST MODELS AND PARAMETER ESTIMATION}

The key to forecasting return is to observe that return is any one period are generated by sales in the preceding periods. A prevalent way of modelling this to assume that a sale in the current period will generate a return $\mathrm{K}$ periods from now with probability $\mathrm{K}, \mathrm{K}=1,2, \ldots \ldots$. or will never be returned. Conflict forecasting methods.

Forecasting methods are often chosen because of popularity ( frequency of use by practitioners) or on the basis of expert judgement.

ARMSTRONG Brodie, and me in Tyre (1987), surveyed forecasting practitioners on their use of six methods for forecasting decision in making and for their assessment of the usefulness of these methods. The authors intended these to an exhaustive list of the methods for forecasting decision in marketing 
( personal communication from J.S Armstrong 29 August 2001).

In chapter four, the responses generated from the questionnaire administered and interview conducted were presented analysed and interpreted and the result were used. To answer the research questions. The hypothesis was tested and it was concluded that there is a significant relationship between tax evasion and revenue generation in Nigeria.

The final chapter, chapter five provides the summary, conclusion and recommendations of the work done.

\section{CONCLUSION}

Based on the findings as stated in the previous sections, it could be concluded that the management of Nigeria Bottling company in depth knowledge of what forecasting is all about, they tend to confuse forecasting with target" set for sales, persons and so are not interested in developing formal process of forecasting.

\section{REFFERENCE}

1. Butter W.F (1975), method and Techniques of Business forecasting practice hall.

2. Cerlin, E.D John, H. (1975), management Decision making analysis the Macmillan, London.

3. Devidson,K. (1981), operation management the Macmillan London.

4. Davis, K. (1968), sales force for management, the Ronald process company.

5. Runker, P. (1974), management Task Responsibility and practice heinemann London.
6. Gluck, W. (1980), management policy Dryden press series .

7. Green, P.E.C. (1978), Research for making Decision 4th Edition. Prentice hall international series.

8. Louder, A.C (1970), operation management, South West publishing company.

9. Monks, V. (1982), operation management theory and problem Mc Graw-hall inc.

10. Morley, V.C. (1972), management Decision and the role of forecasting pengium Book Ltd.

11. Riggs, J. (1972), production system analysis and control.

12. Stage, C. (1978), introduction to management economic Hutchinson Ltd.

13. Spurs, M. (1978) forecasting method and application John Wiley and sons. 